Review article

Central Eur J Paed 2018;14(1):12-21

DOI $10.5457 / \mathrm{p} 2005-114.194$

\title{
Neonatal hypoglycaemia: History, clinical picture, investigations, management and outcome
}

\author{
Tinkara Sluga ${ }^{1}$, Domen Robek ${ }^{2}$, Petja Fister ${ }^{2}$
}

${ }^{1}$ Community Health Centre Ljubljana,

Slovenia, ${ }^{2}$ Department of Neonatology,

Division of Pediatrics, University Medical

Centre Ljubljana, Slovenia

$$
\begin{aligned}
& \text { Correspondence: } \\
& \text { petja_fister@yahoo.com } \\
& \text { Tel.: + } 38615229274 \\
& \text { Fax.: + } 38615224035
\end{aligned}
$$

Received: November 3, 2018

Accepted: December 16, 2018

Key words: Hypoglycaemia - Neonate Blood glucose - Neurological manifestations.
The aim of this article is to present the problem of neonatal hypoglycaemia through clinical cases. Hypoglycaemia is the most common neonatal metabolic disturbance. It may be picked up incidentally in a neonate without clinical signs, or anticipated in a neonate at risk of hypoglycaemia. The lowest accepted blood glucose (BG) concentration is difficult to define, the one most often used in clinical practice it is a BG concentration of $2.2 \mathrm{mmol} / \mathrm{L}$ in the first 24 hours of life and of $2.6 \mathrm{mmol} / \mathrm{L}$ after the first day of life. After birth, transient mild decreases in BG levels are physiological. If hypoglycaemia persists, samples of blood and urine should be taken to diagnose the etiological factor causing it if the condition is not otherwise evident. Conclusion: Since persistent or recurrent hypoglycaemia may cause permanent long-term neurological impairment, it is important to diagnose and treat it appropriately and in good time in order to maintain normoglycaemia and assure normovolemia in a neonate. Moreover, the etiological factors causing hypoglycaemia should be sought so the therapy is also cause-targeted.

\section{Introduction}

\section{Metabolic adaptation in the neonate}

In physiological conditions, glucose is the main substrate for human metabolism and it is the predominant source of energy for the foetal and neonatal brain $(1,2)$. In utero blood glucose $(\mathrm{BG})$ is transferred from maternal to foetal circulation through the placenta with facilitated diffusion that is determined by the high maternal-foetal BG gradient (2). Maternal BG supply may be disrupted due to some maternal or placental conditions. A foetus is able to start using alternative sources of energy (e.g. ketones) and, furthermore, if inadequate BG supply persists, can produce glucose on his or her own by glycogenolysis and gluconeogenesis. Enzymes and hor- mones that participate in glucose metabolism are produced from the 3 th month of gestation onwards (2-4).

After the umbilical cord is clamped, the continuous metabolic supply from the mother is interrupted. During the process of adaptation to an intermittent supply of glucose after birth, the neonate is prone to episodes of hypoglycaemia. Transient postpartum decreases in BG concentrations are physiologi$\mathrm{cal}$ and stimulate neonatal glucose production and appetite (2-7). Hormone changes after birth up-regulate the metabolic pathways by impacting the transcription of genes for metabolic enzymes. The hormones that increase BG concentration in the blood are glucagon, adrenaline, cortisol, adrenocorticotropic hormone (ACTH), growth hormone and thyrox- 
in; insulin and somatostatin have the opposite action and decrease BG (2-5).

The glycogenolysis that predominates shortly after birth is followed by gluconeogenesis in 8 to 12 hours, when glycogen stores are spent. In addition, lipolysis and ketogenesis begin. With the establishment of regular feeding by breast or formula milk, this becomes the main source of energy $(2,4)$. The rate of demand for glucose in the neonate is estimated to be from 4 to $6 \mathrm{mg} / \mathrm{kg} / \mathrm{min}$ and it presumed to be higher in preterm neonates, from 8 to $9 \mathrm{mg} / \mathrm{kg} / \mathrm{min}(3,4)$.

\section{Normal blood glucose concentration}

For each neonate the normal range of $B G$ is different. It depends on feeding status and accessibility of nutrients, gestational age, and birthweight as well as the presence or absence of a maternal or foetal disease. Therefore, the definition of hypoglycaemia remains controversial (4, 8, 9-13). Neonates react differently to low BG and show clinical signs at different BG concentrations. Secondly, many neonates at risk of hypoglycaemia have some other associated risk factors (e.g. hypoxia, stress) that cause and contribute to the clinical picture of hypoglycaemia (14). Finally, studies do not show any unified definition of BG concentration or a critical duration of hypoglycaemia that could lead to neurodevelopmental disturbances $(4,8,9-13)$.

Most clinical guidelines define hypoglycaemia as an arbitrary threshold at which treatment should be started (9). The approach is concentrated on recognition of neonates at risk, in order to lower the consequences of hypoglycaemia and, on the other hand, to prevent overtreatment of transiently lowered BG (4, 8, 9-13). When reading the different guidelines, it should be taken into account that glucose concentration is higher in plasma than in whole blood, and it is also higher in arterial compared to capillary or venous samples. The operational threshold most often used in clinical practice is a BG concentration of $2.2 \mathrm{mmol} / \mathrm{L}$ in the first 24 hours of life and of $2.6 \mathrm{mmol} / \mathrm{L}$ after the first day of life (DOL) $(6,8-10,13,15,16)$.

\section{Transient and persistent hypoglycaemia}

Increased requirements or reduced production of glucose result in hypoglycaemia. Transient postpartum decreases in BG concentrations are physiological. In principle, it is a short-term phenomenon without clinical signs and resolves spontaneously within 24 hours after birth, with regular nutritional input (2-7).

Sometimes, however, a glucose metabolic pathway may permanently be disrupted, causing prolonged or severe hypoglycaemia. If neonatal hypoglycaemia persists for more than 48 hours after birth it is most likely pathological. Causes of pathological hypoglycaemia can be divided into 4 main groups according to the disrupted phase of glucose metabolism: inadequate glucose supply, low glycogen stores, impaired glucose production and increased glucose utilization, with or without hyperinsulinism $(2,4,12,15)$. First, inadequate glucose supply appears when there is insufficient enteral or parenteral nutritional input (5-7). Secondly, low glycogen stores may be a problem in preterm neonates, because glycogen starts to form in the 3rd trimester of pregnancy $(2,5,7,17)$, and also in the case of in utero growth restriction (IUGR) $(2,7,18)$. Thirdly, impaired glucose production is the result of metabolic disturbances of glycogenolysis, gluconeogenesis, amino acid, carbohydrate and fatty acid metabolism (19). In addition, endocrine disorders may cause an imbalance in the hormones participating in glucose metabolism (cortisol, somatostatin, thyroid hormone), as an isolated disorder or as a part of a syndrome (20).

Other conditions that may contribute to low glucose production are: maternal use of beta antagonists (which minimize the effect 
of adrenaline on glycogenolysis) (21), hypothermia (increases glycogen consumption and anaerobic conditions) (22) and severe liver failure (both glycogenesis and glycogenolysis are disturbed) (23). Finally, increased glucose utilization may appear with or without elevated insulin concentration. Hyperinsulinism is generally a transient condition and resolves spontaneously (24). Most often it is the consequence of unregulated maternal diabetes (type 1, type 2 or gestational) (25, 26). Moreover, a transient increase in insulin concentration may be seen in some other conditions: in IUGR $(7,18,27,28)$, after a stressful peripartum event $(2,7,22,29)$, after maternal treatment with insulin or glucose during labour (30), and in the case of some foetal disorders: haemolytic disease of the newborn, hypothermia, heart failure $(2,7$, 22) and in Beckwith-Wiedemann syndrome (BWS) $(24,31,32)$.

However, hyperinsulinism may persist and usually results in severe hypoglycaemia. In almost half of the cases it is caused by mutation of genes coding the enzymes that participate in intracellular metabolism or cation transmembrane transport in the pancreatic beta cells. The genes most often affected are those coding ATP dependent potassium channel proteins on the cell membrane (SUR1, Kir6.2) that control insulin excretion from beta cells. In addition, mutations may be present in some syndromes (BWS, Kabuki, Turner) (7, 24, 33). However, increased glucose utilization can also occur in a normoinsulinemic state. It may be seen in asymmetrical small for gestational age (SGA) neonates that have a disproportionately large head compared to their whole body (18). Furthermore fuel requirements are increased in an anaerobic state (2-5) and also in polycythaemia (34). In sepsis a few factors contribute to low BG: hormonal and inflammatory changes result in higher glucose utilization, glycogen stores are minimised and gluconeogenesis is disturbed (35).

\section{History}

Perinatal history directs the neonatologist to check the BG concentration regularly in a neonate with risk factors for hypoglycaemia. Certain maternal and neonatal conditions predispose the neonate to hypoglycaemia (Table 1) $(6,7,11,36)$.

Neonates with maternal and some temporary neonatal conditions usually have transient hypoglycaemia. On the other hand, persistent or recurrent hypoglycaemia needs further detailed diagnostics and observation. While discussing heteroanamnesis, attention has to be paid to any family history of metabolic or endocrine disturbances or other chronic diseases, maternal health status before and during pregnancy, the course of delivery and the neonatal condition $(2,7,36)$.

\begin{tabular}{l} 
Table 1. The indications for routine monitoring \\
of blood glucose for prevention of neonatal \\
hypoglycaemia. \\
\hline Maternal conditions \\
Diabetes (type I, type II, gestational) \\
Preeclampsia, eclampsia, hypertension \\
Previous macrosomic infants \\
Forbidden substance abuse \\
Treatment with beta-antagonists, tocolytics, oral \\
hypoglycaemic agents \\
Peripartal administration of intravenous glucose or \\
insulin \\
Neonatal conditions \\
Premature or post term neonate \\
Small or large for gestational age neonate \\
Perinatal asphyxia \\
Sepsis \\
Hypothermia \\
Polycythemia-hyperviscosity \\
Erythroblastosis foetalis \\
Iatrogenic administration of insulin \\
Congenital heart defect \\
Persistent hyperinsulinemia \\
Endocrine disorders and inborn errors of metabolism \\
\hline
\end{tabular}




\section{Clinical picture}

Neonates with hypoglycaemia often have no signs of metabolic disruption or may have non-specific signs. Autonomic nervous system activation and adrenaline cause neurogenic-autonomic signs: most often tremor but rarely other signs (pallor, cyanosis, tachycardia, tachypnea, diaphoresis, vomiting, apnoea and cardiac arrest). Neurological clinical signs, such as muscle hypotonia, and infrequently poor feeding, abnormal cry, hypothermia, lethargy, coma, irritability and seizures, occur as a result of neuroglycopenia $(4,6,7,9,12)$.

During examinations of newborns we are specifically alert to the signs of hypoglycaemia enumerated, signs of sepsis, shock, birth measurements, organomegaly, jaundice, and neurological status, as well as certain dysmorphic features which could lead us to the aetiology of hypoglycaemia (Table 2$)(2,7,36)$.

\section{Investigations}

On the basis of any known maternal and neonatal conditions, as well as a clinical examination of the neonate, screening for hypoglycaemia should be done in selected neonatal population at predetermined times, as well as in neonates with clinical signs of hypoglycaemia at the time of observation (Table 3) $(6,7,11,36,37)$.

The method used for detection of low BG must be quick, accurate and reliable. Measurement is usually initially done using bedside glucose reagent strips from capillary blood. Since this device was primarily created for checking elevated BG in diabetic patients, it is not accurate enough in a range of low BG. Although more precise glucometers are being invented (24), in the case of a low BG, a blood sample should be sent to the laboratory for confirmation using a more precise method $(6,16)$. A blood sample of capillary or venous blood should be checked within a reasonable time in order to prevent erythrocyte glycolysis and a false low BG reading $(7,22)$. The treatment should be initiated on the basis of the bedside test without waiting for laboratory results (6).

In cases of early transient hypoglycaemia, we determine plasma glucose, complete blood count with white blood cell differential and C-reactive protein. In persistent or clinically evident hypoglycaemia, samples of blood and urine should be taken to diagnose the etiological factor causing it (Table 4). A so-called "critical sample" of blood has to be taken during an episode of hypoglycaemia $(7,36,38)$. Combining the results helps in determination of the cause of hypoglycaemia (Fig. 1).

Table 2. The type of hypoglycaemia, clinical features and aetiology of neonatal hypoglycaemia.

\begin{tabular}{lll}
\hline Type of hypoglycaemia & Clinical feature & Aetiology \\
\hline \multirow{2}{*}{ Transient hypoglycaemia } & Inappropriate foetal growth & Small or large for gestational age neonate \\
\cline { 2 - 3 } & Plethora & Polycythemia-hyperviscosity \\
\cline { 2 - 3 } & Hepatosplenomegaly & $\begin{array}{l}\text { Sepsis, erythroblastosis foetalis, exchange } \\
\text { transfusion, congenital heart disease }\end{array}$ \\
\cline { 2 - 3 } & Abnormal neurological signs & Perinatal asphyxia \\
\hline \multirow{3}{*}{$\begin{array}{l}\text { Prolonged } \\
\text { hypoglycaemia }\end{array}$} & $\begin{array}{l}\text { Hepatosplenomegaly } \\
\text { Hepatomegaly, enlarged tongue, }\end{array}$ & Glycogenosis \\
\cline { 2 - 3 } & Jaundice, poor weight gain, lethargy & Hypothyroidism, adrenal insufficiency \\
\cline { 2 - 3 } & Jaundice, micropenis, ocular nerve hypoplasia & Panhypopituitarism, septo-optic dysplasia \\
\cline { 2 - 3 } & Lethargy, coma, vomiting, peculiar odour & Hyperammoniaemia, lactacidosis, urea cycle diseases \\
\hline
\end{tabular}

BWS=Beckwith-Wiedemann syndrome. 


\section{Table 3. Screening for hypoglycaemia according to known maternal and neonatal conditions.}

\begin{tabular}{|c|c|}
\hline Maternal and neonatal conditions & Glucose sampling timing \\
\hline $\begin{array}{l}\text { SGA } \\
\text { Infant of diabetic mother } \\
\text { Maternal labetalol or tolbutamide therapy } \\
\text { Preterm or sick term neonate }\end{array}$ & $\begin{array}{l}\text { Pre second feed, continue until two consecutive measures }>2.6 \mathrm{mmol} / \mathrm{L} \text {. Then } 2 \\
\text { hours and 6-12 hourly until levels readily above } 2.5 \mathrm{mmol} / \mathrm{L} \text {, then daily when on } \\
\text { total parenteral nutrition and at other times when clinically indicated. }\end{array}$ \\
\hline Perinatal asphyxia & On admission; 2, 6, 12, 24 hours or regularly during serious illness. \\
\hline Haemolytic disease of the newborn & 1,2 and 4 hours after exchange transfusion. \\
\hline Fitting or excessive jittering & Immediately. \\
\hline
\end{tabular}

$S G A=$ Small for gestational age.

Table 4. Blood sample ("critical sample") to be taken during hypoglycaemia to determine the aetiology.

\begin{tabular}{llll}
\hline Blood sample & & & Urine sample \\
\hline Hormones & Metabolites & Other & Metabolites \\
\hline Insulin & Glucose & $\mathrm{pH}$ & Ketones \\
Cortisol & Free fatty acids & Galactose-1-phosphate & Reducing \\
Growth hormone & Beta-OH butyrate & Uridyl transferase & Organic acids \\
Adrenocorticotropic hormone & Lactate & & Amino acids \\
Thyroid stimulating hormone & Amino acids & & \\
Thyroxin & Pyruvate & & \\
C-peptide & Acetoacetate & & \\
Glucagon & Urate & & \\
& Lipids & & \\
& Total and free carnitine & & \\
& Acyl carnitine profile & & \\
& Ammonia & & \\
& & & \\
& &
\end{tabular}

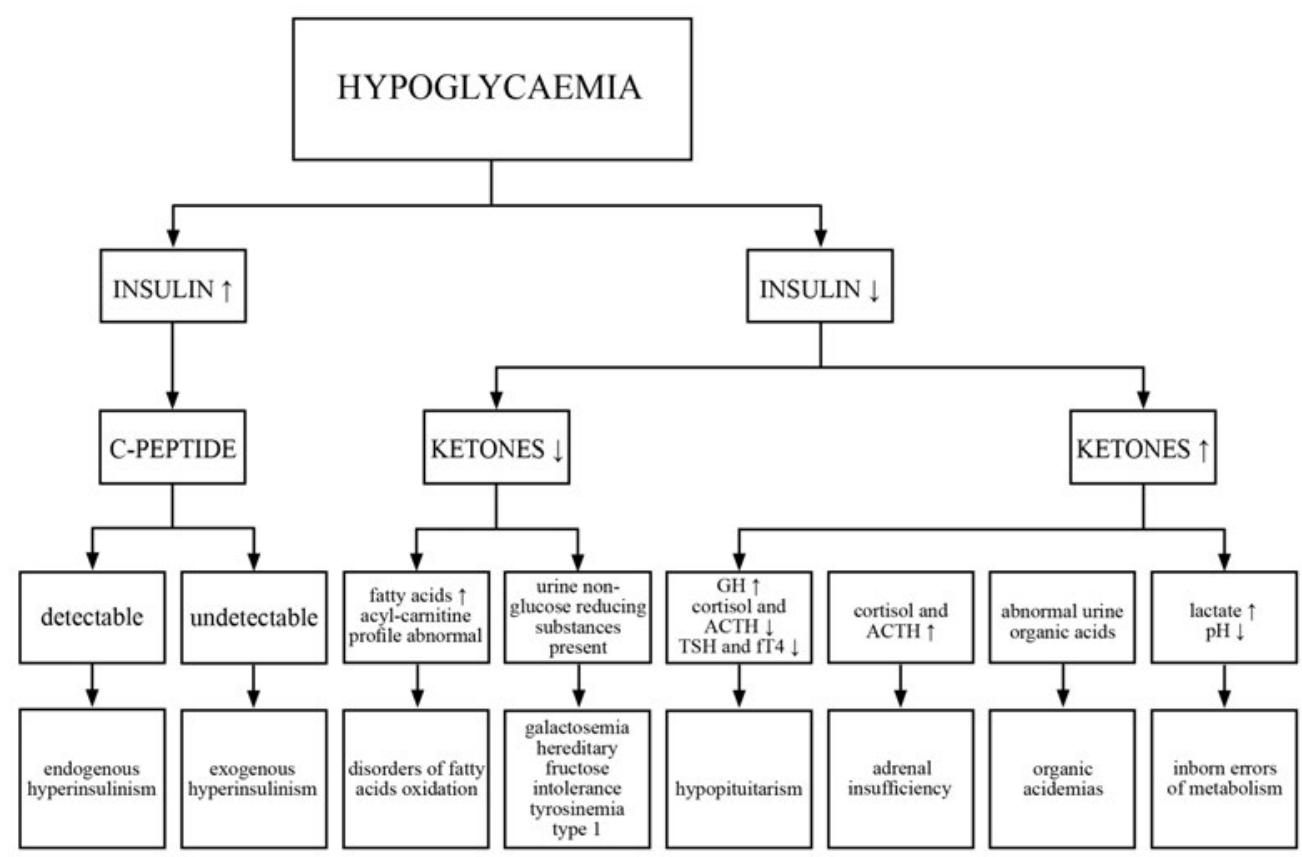

Fig. 1. The diagnostic algorithm of hypoglycaemia for the interpretation of the laboratory results.

$\mathrm{GH}=$ growth hormone; $\mathrm{ACTH}=$ adrenocorticotropic hormone; $\mathrm{TSH}=$ thyroid stimulating hormone; $\mathrm{fT} 4=$ free thyroxin. 
Furthermore, additional focused investigations are warranted. Congenital central nervous system malformations may be diagnosed using ultrasound (US) and magnetic resonance imaging (MRI) of the brain (29, 39-41). Adrenal haemorrhage, pancreas hypertrophy and hepatomegaly may be visualized by US or MRI of the abdomen (42). Ophthalmological examination poses suspicion of septo-optic dysplasia (43).

\section{Management}

The main goal of treatment of neonatal hypoglycaemia is to correct the BG concentration in order to prevent the development of clinical signs, and to minimize the occurrence of long-term neurologic sequelae. Some general clinical practices may contribute to prevention of the event of hypoglycaemia in a healthy neonate. The emphasis should be laid on encouragement of early breastfeeding within the first hour of life and then regular breastfeeding or complementary feeds every 3 hours. The maintenance of a thermoneutral environment also helps to prevent hypothermia. In the presence of hypoglycaemia, appropriate management should be started according to the clinical signs, the BG concentration and other co-existing conditions (Fig. $2)$. The BG concentration should be checked 20 minutes after the initiation of treatment $(2,5-8,24,33,36,44,45)$.
Sometimes hypoglycaemia persists despite parenteral glucose treatment, therefore additional medication should be administrated (Table 5). Glucagon is a short-acting agent, hence boluses have to be repeated or continuous infusion should be initiated $(2,46)$. Therapy with glucocorticoids is time limited to 1 or 2 days because of their many side effects, except in adrenal insufficiency, where long-term supplemental therapy is needed $(2,24,45)$. In persistent hyperinsulinemic hypoglycaemia the first choice treatment is diazoxide, but if there is no response to it, octreotide may be used (44). In rare cases partial or total pancreatectomy is needed (2, $33,45)$.

After maintaining BG within the normoglycaemic range with therapy, the goal should be to gradually stop glucose supplementation and other medications, and to maintain normal BG concentrations with regular oral feeding. BG must be checked before meals $(6,7,24)$.

\section{Outcome}

Short-term mild transient hypoglycaemia, without clinical signs, usually shows no neurodevelopmental sequelae. Persistent or recurrent hypoglycaemia with a developed clinical picture, especially if manifesting as seizures, might be associated with abnormal neurodevelopmental outcomes $(8,17,47-$

Table 5. Additional medications for persistent hypoglycaemia.

\begin{tabular}{lll}
\hline Therapy & Effect & Dosage \\
\hline \multirow{2}{*}{ Glucagon } & $\begin{array}{l}\text { Stimulates glicogenolysis } \\
\text { Releases glycogen from hepatic stores when insulin } \\
\text { concentrations are normal }\end{array}$ & $\begin{array}{l}20 \mathrm{do} 30 \mathrm{mcg} / \mathrm{kg} \text { i.m., s.c., i.v. } \\
1 \mathrm{mg} / 24 \mathrm{hrs}(10-20 \mathrm{mg} / \mathrm{kg} / \mathrm{hr}) \mathrm{inf} .\end{array}$ \\
\hline Corticosteroids & $\begin{array}{l}\text { Decrease peripheral glucose utilization } \\
\text { Enhance gluconeogensis }\end{array}$ & $\begin{array}{l}\text { Hydrocortisone i.v., p.o. } \\
\text { Diazoxide }\end{array}$ \\
\hline Octreotide & $\begin{array}{l}\text { As potassium channel activator on beta pancreatic cells inhibits } / \mathrm{kg} / \mathrm{day} \text { in } 2-3 \text { daily doses } \\
\text { insulin excretion }\end{array}$ & $15 \mathrm{mg} / \mathrm{kg} / \mathrm{day}$ \\
\hline Pancreatectomy & $\begin{array}{l}\text { As a somatostatin analogue inhibits glucagon, somatostatin and } \\
\text { insulin release }\end{array}$ & $5-10 \mathrm{mcg} / \mathrm{kg}$ every 6-8 hr \\
\hline
\end{tabular}




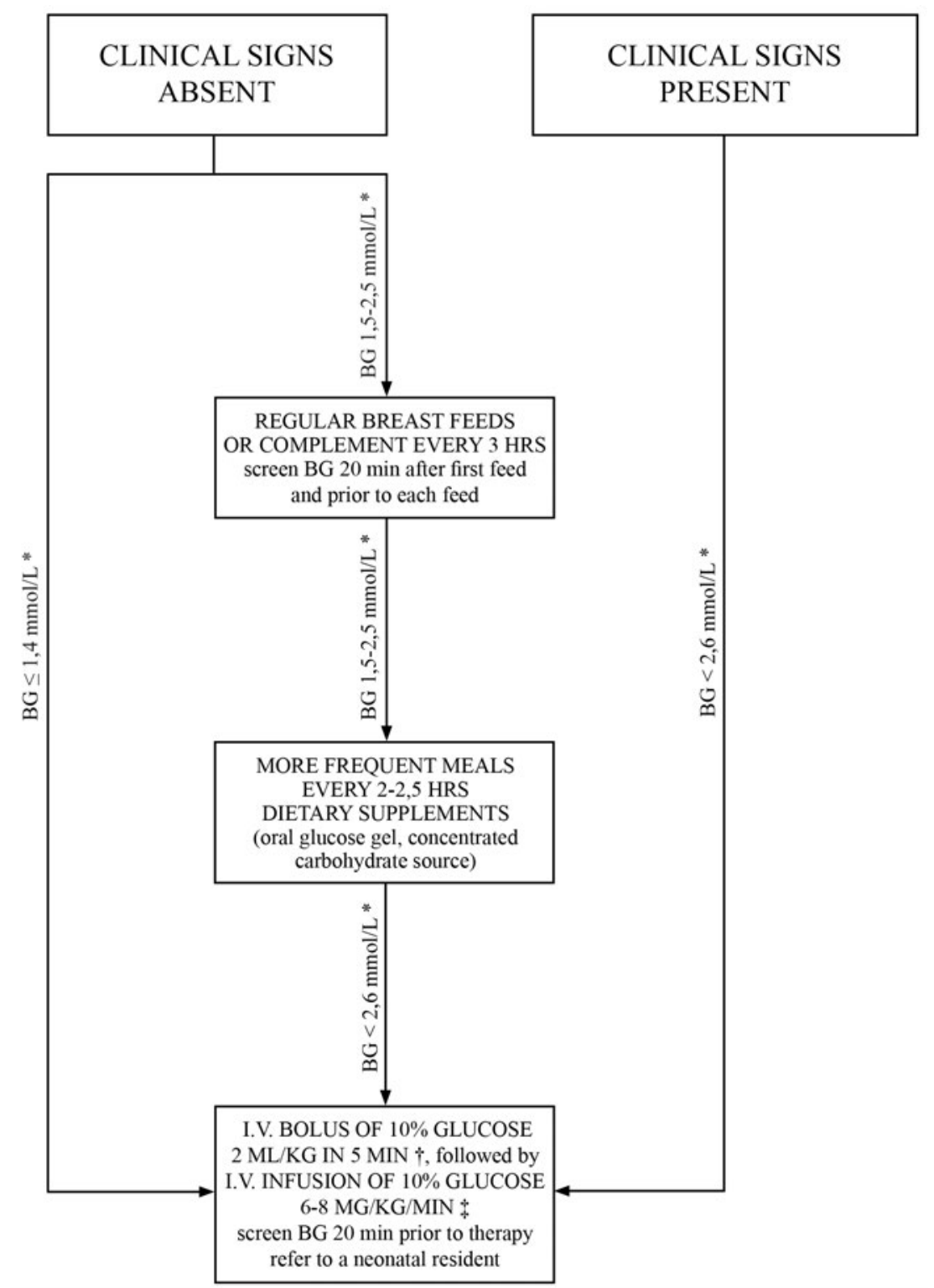

Fig. 2. Management of neonatal hypoglycaemia.

*Levels are arbitrary.

$\dagger$ Bolus application of glucose is not recommended in neonates without clinical signs since fast changes in BG can cause more neuro-developmental deficits than hypoglycaemia in a clinically stable neonate (8).

$¥$ A rate of i.v. infusion has to be adjusted to fluid demands. Moreover, glucose concentrations can be raised if necessary, to a maximum $12.5 \%$ in a peripheral approach and to maximum $25 \%$ in a central approach $(2,6,7,24,45)$.

50). Due to the frequent other co-existing pathological conditions in neonates, it is hard to define which neurological deficits result from low BG concentrations (51). Brain injury is unspecific and, especially in the case of hypoglycaemia with clinical signs, can be seen on MRI $(40,41,52)$. It has not been proven that neurologic sequelae could be pre- 
vented with therapy, nevertheless aggressive treatment is advised $(6,7,36)$. All infants with hypoglycaemia should be followed up for neurodevelopmental sequelae (36).

\section{Conclusion}

Since low BG is physiological a few hours after birth, the main goal is to recognise persistent or recurrent hypoglycaemia in a neonate and start treatment as soon as possible, in order to prevent brain damage. Low BG may also be a warning sign as part of more complex disorders. Clinical and additional laboratory findings can indicate the possible aetiology of hypoglycaemia, enabling causetargeted management. When hypoglycaemia is controlled and normoglycaemia is achieved with regular meals or appropriate therapy, the neonate may be discharged home. Follow-up of neonates who have had persistent or recurrent hypoglycaemia is warranted to watch for changed metabolic and endocrine pathways.

Conflict of interest: The authors declare that they have no conflict of interest.

\section{References}

1. Cunnane SC. Human brain evolution: A question of solving key nutritional and metabolic constraints on mammalian brain development. In: Cunnane SC, Stewart KM. Human brain evolution: The influence of freshwater and marine food resources. 1st ed. New Jersey: John Wiley and Sons Inc. 2010:41-2.

2. McGowan JE. Neonatal hypoglycemia. Pediatr Rev. 1999;20:6e-15.

3. Hay WW Jr. Recent observations on the regulation of fetal metabolism by glucose. J Physiol. 2006;572:17-24.

4. Rozance PJ, Hay WW. Describing hypoglycemia - definition or operational threshold? Early Hum Dev. 2010;86:275-80.

5. Tin W, Brunskill G, Kelly T, Fritz S. 15-year follow-up of recurrent "hypoglycemia" in preterm infants. Pediatrics. 2012;130:1497-1503.
6. Adamkin DH, Committee on Fetus and Newborn. Clinical report - Postnatal glucose homeostasis in late-term and preterm infants. Pediatrics. 2011;127:575-9.

7. Stanley CA, Rozance, PJ, Thornton PS, De Leon DD, Harris D, Haymond MW, et al. Re-evaluating "transitional neonatal hypoglycemia": mechanism and implications for management. J Pediatr. 2015;166:1520-5.

8. McKinlay CJ, Alsweiler JM, Ansell JM, Anstice NS, Chase JG, Gamble GD, et al. Neonatal glycemia and neurodevelopmental outcomes at 2 years. N Engl J Med. 2015;373:1507-18.

9. Cornblath M, Hawdon JM, Williams AF, AynsleyGreen A, Ward-Platt MP, Schwartz R, et al. Controversies regarding definition of neonatal hypoglycemia: suggested operational thresholds. Pediatrics. 2000;105:1141-5.

10. Hay WW, Raju TNK, Higgins RD, Kalhan SC, Devaskar SU. Knowledge gaps and research needs for understanding and treating neonatal hypoglycemia: workshop report from Eunice Kennedy Shriver National Institute of Child Health and Human Development. J Pediatr. 2009;155:612-7.

11. Screening guidelines for newborns at risk for low blood glucose. Paediatr Child Health. 2004;9:72340.

12. Sperling MA. Hypoglycaemia. In: Robert Kliegman R, Stanton B, St Geme J, Schor N. Nelson textbook of pediatrics. 20th ed. Philadelphia: Saunders Elsevier Itc. 2015:773-88.

13. Tin W. Defining neonatal hypoglycaemia: a continuing debate. Semin Fetal Neonatal Med. 2014;19:27-32.

14. Volpe JJ. Hypoglycemia and brain injury. In: Volpe JJ. Neurology of the newborn. 5th edition. Philadelphia: Saunders Elsevier Itc. 2008:591-618.

15. McGowan JE. Commentary, neonatal hypoglycemia. Fifty years later, the questions remain the same. NeoReviews. 2004;5:e363-4.

16. Rozance PJ, Hay WW. Hypoglycemia in newborn infants: Features associated with adverse outcomes. Biol Neonate. 2006;90:74-86.

17. Kerstjens JM, Bocca-Tjeertes IF, de Winter AF, Reijneveld SA, Bos AF. Neonatal morbidities and developmental delay in moderately preterm-born children. Pediatrics. 2012;130:e265-72.

18. Sinclair JC, Bottino M, Cowett RM. Interventions for prevention of neonatal hyperglycemia in very 
low birth weight infants. Cochrane Database Syst Rev. 2009;3:CD007615.

19. Worthen HG, al Ashwal A, Ozand PT, Garawi S, Rahbeeni Z, al Odaib A, et al. Comparative frequency and severity of hypoglycemia in selected organic acidemias, branched chain amino acidemia, and disorders of fructose metabolism. Brain Dev. 1994;16Suppl:81-5.

20. Samaan NA. Hypoglycemia secondary to endocrine deficiencies (abstract). Endocrinol Metab Clin North Am. 1989;18:145.

21. Bateman BT, Patorno E, Desai RJ, Seely EW, Mogun $\mathrm{H}$, Maeda $\mathrm{A}$, et al. Late pregnancy $\beta$ blocker exposure and risks of neonatal hypoglycemia and bradycardia. Pediatrics. 2016;138.

22. Shankaran S. Therapeutic hypothermia for neonatal encephalopathy. Curr Treat Options Neurol. 2012;14:608-19.

23. Cochran JB, Losek JD. Acute liver failure in children. Pediatr Emerg Care. 2007;23: 129-35.

24. Vora S, Chandran S, Rajadurai VS, Hussain L. Hyperinsulinemic hypoglycemia in infancy: Current concepts in diagnosis and management. Indian Pediatrics. 2015;52:1051-9.

25. Hay WW. Care of the infant of the diabetic mother. Curr Diab Rep. 2012;12:4-15.

26. VanHaltren K, Malhotra A. Characteristics of infants at risk of hypoglycaemia secondary to being 'infant of a diabetic mother'. J Pediatr Endocrinol Metab. 2013;26:861-5.

27. Arya VB, Flanagan SE, Kumaran A, Shield JP, Ellard S, Hussain K, et al. Clinical and molecular characterisation of hyperinsulinaemic hypoglycaemia in infants born small-for-gestational age. Arch Dis Child Fetal Neonatal Ed. 2013;98:F356-8.

28. Fafoula O, Alkhayyat H, Hussain K. Prolonged hyperinsulinaemic hypoglycaemia in newborns with intrauterine growth retardation. Arch Dis Child Fetal Neonatal Ed. 2006;91:F467.

29. Boardman JP, Hawdon JM. Hypoglycaemia and hypoxic-ischaemic encephalopathy. Dev Med Child Neurol. 2015;57(Suppl 3):29-33.

30. Kalra P, Anakal M. Peripartum management of diabetes. Indian J Endocrinol Metab. 2013;17:72-6.

31. Munns C, Batch J. Hyperinsulinism and BeckwithWiedemann syndrome. Arch Dis Child Fetal Neonatal Ed. 2001;84:F67-9.
32. Hussain K, Cosgrove KE, Shepherd RM, Luharia A, Smith VV, Kassem S, et al. Hyperinsulinemic hypoglycemia in Beckwith-Wiedemann syndrome due to defects in the function of pancreatic betacell adenosine triphosphate-sensitive potassium channels. J Clin Endocrinol Metab. 2005;90:437682.

33. Stanley CA. Perspective on the genetics and diagnosis of congenital hyperinsulinism disorders. J Clin Endocrinol Metab. 2016;101:815-26.

34. Sukadi A, Endropranoto SF, Suwarno W, Sastranegara $\mathrm{H}$. The association between neonatal polycythemia, hypocalcemia, and hypoglycemia. Paediatr Indones. 1989;29:141-5.

35. Ahmad S, Khalid R. Blood glucose levels in neonatal sepsis and probable sepsis and its association with mortality. J Coll Physicians Surg Pak. 2012;22:15-8.

36. Thornton PS, Stanley CA, De Leon DD, Harris D, Haymond MW, Hussain K, et al. Recommendations from the Pediatric endocrine society for evaluation and management of persistent hypoglycemia in neonates, infants, and children. J Pediatr. 2015;167:238-45.

37. Rennie JM, Kendall GS. Metabolic disorders, including glucose homeostasis and inborn errors of metabolism. In: Rennie JM, Kendall GS. A manual of neonatal intensive care, 5 th ed. New York: CRC Press. 2013:236-44.

38. Ogilvy-Stuart A, Midgley P. Hypoglycaemia. In: Ogilvy-Stuart A, Midgley P. Practical neonatal endocrinology. Cambridge: Cambridge University Press. 2006:7-16.

39. Su J, Wang L. Research advances in neonatal hypoglycemic brain injury. Transl Pediatr. 2012;1:10815.

40. Burns CM, Rutherford MA, Boardman JP, Cowan FM. Patterns of cerebral injury and neurodevelopmental outcomes after symptomatic neonatal hypoglycemia. Pediatrics. 2008;122:65-74.

41. Kinnala A, Rikalainen H, Lapinleimu H, Parkkola R, Kormano M, Kero P. Cerebral magnetic resonance imaging and ultrasonography findings after neonatal hypoglycemia. Pediatrics. 1999;103:724-9.

42. Nijs E, Callahan MJ, Taylor GA. Disorders of the pediatric pancreas: imaging features. Pediatr Radiol. 2005;35:358-73.

43. Berger S, Bosmia AN. Diagnosis of septo-optic dysplasia in a neonate with hypernatremia, hypo- 
glycemia, and persistent hypothermia. J Pediatr Endocrinol Metab. 2013;26:1167-9.

44. Kumar J, Singh A. A brief review of hyperinsulinism in small for gestational age infants. J Med Sci Clin Res. 2017;5:15379-83.

45. Sweet CB, Grayson S, Polak M. Management strategies for neonatal hypoglycemia. J Pediatr Pharmacol Ther. 2013;18:199-208.

46. Miralles RE, Lodha A, Perlman M, Moore AM. Experience with intravenous glucagon infusions as a treatment for resistant neonatal hypoglycemia. Arch Pediatr Adolesc Med. 2002;156:999-1004.

47. Menni F, de Lonlay P, Sevin C, Touati G, Peigne C, Barbier V, et al. Neurologic outcomes of 90 neonates and infants with persistent hyperinsulinemic hypoglycemia. Pediatrics. 2001;107:476-9.

48. Steinkrauss L, Lipman TH, Hendell CD, Gerdes M, Thornton PS, Stanley CA. Effects of hypoglycemia on developmental outcome in children with congenital hyperinsulinism. J Pediatr Nurs. 2005;20:109-18.

49. Meissner T, Wendel U, Burgard P, Schaetzle S, Mayatepek E. Long-term follow-up of 114 patients with congenital hyperinsulinism. Eur J Endocrinol. 2003;149:43-51.

50. Kaiser JR, Bai S, Gibson N, Holland G, Lin TM, Swearingen CJ, et al. Association between transient newborn hypoglycemia and fourth-grade achievement test proficiency: A population-based study. JAMA Pediatr. 2015;169:913-21.

51. Boluyt N, van Kempen A, Offringa M. Neurodevelopment after neonatal hypoglycemia: a systematic review and design of an optimal future study. Pediatrics. 2006;117:2231-43.

52. Tam EW, Widjaja E, Blaser SI, Macgregor DL, Satodia P, Moore AM. Occipital lobe injury and cortical visual outcomes after neonatal hypoglycemia. Pediatrics. 2008;122:507-12. 